\title{
Synthesis of Medium-Sized Lactones from Siloxy Alkynes and Lactols by Ring Expansion
}

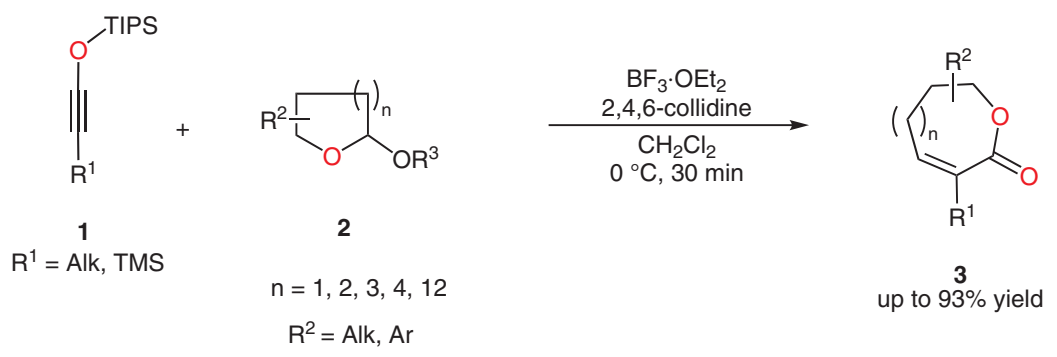

\section{lactones}

ring expansion

alkynes

lactols

\section{Selected examples:}

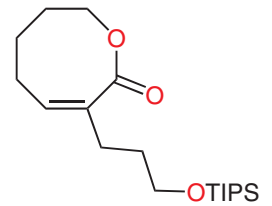

$3 a$

$62 \%$ yield<smiles>CCCCC1=CCC(OC)[C@H](COC)OC1=O</smiles>

3b

$46 \%$ yield<smiles>CC(C)(C)C1=CCCC(c2ccccc2)OC1=O</smiles>

$3 c$

$72 \%$ yield<smiles>CCCCC1=CCCCCCCOC1=O</smiles>

$3 d$

$88 \%$ yield
Significance: Medium-sized lactones are structural motifs found in many bioactive molecules and natural products (see Review below). Moreover, their synthesis is challenging due to unfavorable kinetic and thermodynamic factors in their formation, as especially evident in macrolactonization approaches and ring-closing metathesis strategies. Such approaches often require dilute reaction conditions or slow addition of substrate to obtain good yields of the desired product. As an alternative, intermolecular reactions can provide entry to medium-sized lactones (see: W. Zhao, W. Wang, J. Sun Angew. Chem. Int. Ed. 2012, 51, 6209).

Review: I. Shiina Chem. Rev. 2007, 107, 239-273.
Comment: The current article describes the synthesis of medium-sized lactones 3 by the reaction of siloxy alkynes $\mathbf{1}$ with cyclic lactols $\mathbf{2}$ through an oxetane ring expansion. The preferred conditions were identified by screening various Lewis acids, Bronsted acids, and additives. A study of the scope of the reaction showed that five-, six-, seven-, eight- and twelve-membered cyclic lactols 2 are well tolerated. The reaction conditions permit the efficient synthesis of medium-sized lactones without the need to use dilute conditions or slow addition of substrates. 